\title{
Industry 4.0: Building of Smart factories of tomorrow
}

\author{
Miroslav Fusko ${ }^{1}$, Radovan Skokan ${ }^{1}$, Iveta Medvecká ${ }^{1}$ \\ ${ }_{1}$ University of Žilina, Faculty of Mechanical Engineering, Department of Industrial \\ Engineering \\ Univerzitná 1, 01026 Žilina, Slovakia \\ miroslav.fusko@fstroj.uniza.sk \\ radovan.skokan@fstroj.uniza.sk \\ iveta.medvecka@fstroj.uniza.sk
}

\begin{abstract}
Annotation: This article deals with Smart factories and their building, benefits and transformation impacts on conventional factories. Important part will be also digital twin in smart factories. Imagine walking into a factory that resembles a high-tech research lab. It is a stark contrast to the image of manufacturing industries we have in our mind, except that this is not a dream or the distant future anymore because we are much closer to this image than you really think. Welcome to the world of smart factories - the new frontier of efficient manufacturing and production.
\end{abstract}

\section{Introduction}

A smart factory, as the name suggests, is a manufacturing or production facility that is highly digitized, a place where the systems are interconnected with each other, and data is exchanged about each aspect of production in real-time. This communication flows smoothly and seamlessly between the different systems and the entire production process happens automatically without any human interference. A key aspect of smart factories is data. When data flows through systems to achieve connected operations, the facility as a whole is able to learn and adapt to the changing needs of the business. In other words, smart factories are intelligent production systems that learn on-the-go and adapt dynamically to changes. Smart factories achieve this high level of automation and efficiency using a myriad of technologies such as artificial intelligence (AI), Internet of Things (IoT), Digital Twin, machine-tomachine communication (M2M) and more. In addition, the term "smart factory" also includes the connection between a shop floor and its overall supply chain through an interconnected IT landscape for a smooth inflow and outflow of materials to and from the industry respectively. [1] Due to such drastic changes in operations, smart factories are often seen as the fourth industrial revolution - popularly known as Industry 4.0 - and they will combine physical machines with business processes to make complex decisions related to efficiency and optimization without a human touch. 


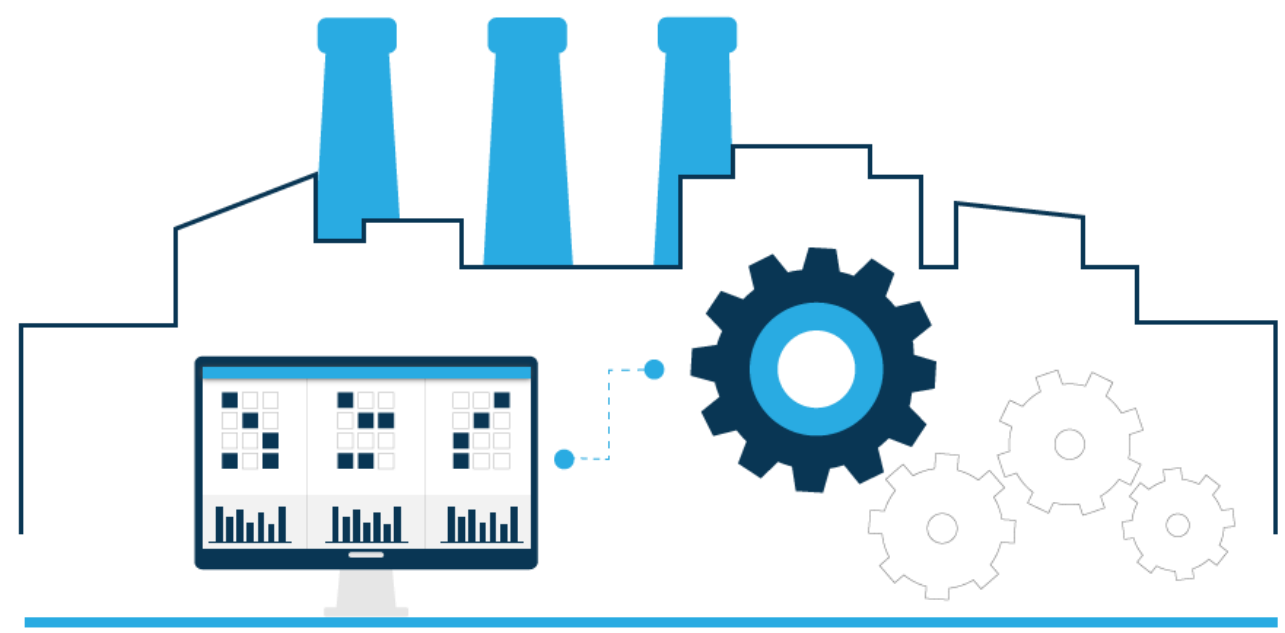

Figure 1 - Concept of Smart factory

Most manufacturers believe they are leading their markets in Industry 4.0 technologies, despite evidence to the contrary. There is a huge gap between the many companies that are exploring digital manufacturing strategies - via technologies such as automation, robotics, Al, and the Internet of Things and those that are implementing them successfully. With Brexit looming, many manufacturers and solutions providers fear what this will mean for the wider European industrial community, which depends on the free movement of people and confident investment. Despite a mixed political outlook in Europe, manufacturers can be optimistic that emerging technologies offer the means to become more efficient, productive and profitable. Worldwide, companies are currently piloting an average of eight different Industry 4.0 solutions, mainly across connectivity, intelligence and flexible automation. The World Economic Forum (WEF) recently released a list of what it says are nine of the world's smartest factories when it comes to adopting industrial loT (IloT) technologies. [2] Five of the so-called 'lighthouse factories' are located in Europe. According to the WEF, their geographic distribution demonstrates that while Europe "may have struggled to produce its own homegrown internet giant, the region remains a powerhouse when it comes to applying advanced technology to manufacturing." These companies all have several things in common: agile teams with a domain, analytics, loT and software development expertise; a common data/loT platform; and up to 15 use cases already in action. They are thinking about scale and are agile. The Fourth Industrial Revolution is delivering productivity gains and transforming the future of manufacturing, but the movement is far from over. The confluence of a range of technologies will shift manufacturing away from monolithic processes based on the lowest labour cost and towards more personalised, automated, and localised value chains, based on customer need. 


\section{Methodology}

While automation and controls have existed for decades, the fully smart factory has only recently gained traction as a viable pursuit for manufacturers. Five overarching trends seem to be accelerating the drive toward smart factories:

- Rapidly evolving technological capabilities.

- Increased supply chain complexity and global fragmentation of production and demand.

- Growing competitive pressures from unexpected sources.

- Organizational realignments resulting from the marriage of IT and OT.

- Ongoing talent challenges, as described below.

\section{Impacts of transform conventional factories into Smart factories}

Manufacturers can implement the smart factory in many different ways - both inside and outside the four walls of the factory - and reconfigure it to adjust as existing priorities change or new ones emerge. In fact, one of the most important features of the smart factory - agility - also presents manufacturers with multiple options to leverage digital and physical technologies depending on their specific needs. The specific impacts of the smart factory on manufacturing processes will likely be different for each organization. The smart factory represents a leap forward from more traditional automation to a fully connected and flexible system. The smart factory is a flexible system that can self-optimize performance across a broader network, self-adapt to and learn from new conditions in real or near-real time, and autonomously run entire production processes. [3]

Is the Smart factory real today? How far along are we? Though we are a few years away from having the perfectly automated smart factory, the good news is many companies have started implementing the myriad aspects of a smart factory and they are seeing the benefits as well. Let's take a look at some key benefits a business can get from these smart factories.

\section{Improves efficiency}

Smart factories bridge the gap between control systems and their onpremises implementation by bringing together both the physical and digital systems. This means smart factories combine control systems, data systems, and physical systems to reduce time lags in the production process. In turn, this leads to higher efficiency and better utilization of available resources. [4] Smart factories can produce output at a staggering rate compared to traditional industries, and that too within the shortest possible time. 


\section{Optimizes assets}

Smart factories optimize different assets and help an organization to get the most out of them. It helps to identify the performance and location of your people, equipment, and resources in real-time so you can make the necessary inventory changes on-the-fly. Also, it helps the organization to tap into the synergy of all these resources working together in order to gain a significant advantage in productivity and revenue.

\section{Predictive maintenance}

According to a report by eMaint, businesses spend 80 per cent of their time reacting to maintenance issues rather than preventing them. This translates to a huge drain of resources including employee productivity, time, and money. Smart factories overcome this problem with proactive predictive maintenance capability. This gives users early warnings when a machine's or network's performance is going to go down, so the team can take the necessary measures to fix the same. Hence, no downtime or losses accrue to the business.

\section{Quality}

The self-optimization that is characteristic of the smart factory can predict and detect quality defect trends sooner and can help to identify a discrete human, machine, or environmental causes of poor quality. This could lower scrap rates and lead times and increase fill rates and yield. A more optimized quality process could lead to a better-quality product with fewer defects and recalls.

\section{Enhances collaboration}

The performance of machines and the overall visibility of your production facility extend way beyond the four walls where your machines are kept. If is the supply chain with production facility connect, it creates a dynamic workflow that provides the necessary information to every related team within an organization. [5] This enhances collaboration, increases productivity, and ensures the smooth conduct of operations from the beginning to end.

\section{Scalable infrastructure}

When you set up the infrastructure for the first time, the capital costs are high. But over time, the infrastructure becomes highly cost-effective because it can be expanded easily to meet the growing needs of business. Also, infrastructure will enhance productivity, safety, and security, so we don't have to spend additional money on these aspects. As a bonus, smart factory will comply with all security practices and specifications laid down by different statutory bodies.

\section{Better mobility for employees}

Employees and supervisors have the option to move around the factory floor and access data from any system to check the efficiency of production systems. [6] This enhances their role, increases their productivity, 
and improves their overall motivation to be a part of the organization. It boosts creativity as well and can open up opportunities for employees to design and implement new solutions.

\section{Safety and sustainability}

The Smart factory can also impart real benefits around labour wellness and environmental sustainability. The types of operational efficiencies that a smart factory can provide may result in a smaller environmental footprint than a conventional manufacturing process, with greater environmental sustainability overall. [7] Greater process autonomy may provide for less potential for human error, including industrial accidents that cause injury. The smart factory's relative self-sufficiency will likely replace certain roles that require repetitive and fatiguing activities. However, the role of the human worker in a smart factory environment may take on greater levels of judgment and on-the-spot discretion, which can lead to greater job satisfaction and a reduction in turnover.

\section{Digital Twin}

The concept of a digital twin came into being in the 1980s, but at that time this concept was called a mirror model. With the advent of the 21st century and the development of new information technology, the reduction in the cost of various types of sensors and the pressure of Industry 4.0, this concept is referred to as a digital twin.

The digital twin represents the digital model of the physical system, object, etc. The digital twin concept was initially used to create a digital copy of the product, but it was later found that the concept could be used in all areas of industry, whether it was designing a new product prototype, creating a digital twin product, production machine, production line, even the creation of a digital twin of the entire manufacturing business.

The concept of a digital factory is the cornerstone of the creation of a digital twin. Using a variety of software solutions or reverse engineering, the digital factory was able to transform the entire production hall into a digital environment.

The digital twin extends this concept to data that arises in the manufacturing plant and which the manufacturing companies could not work with for a long time. Using various types of sensors, intelligent manufacturing, and logistics systems, we can collect this data. With the help of wireless technologies, we can move this data, with cloud solutions we can store this data and with the help of databases, we can process this data in a digital environment, socalled. in a digital twin.

Therefore, a digital twin is not just a copy as it was in a digital enterprise, but a digital twin is a complete copy of a real production system with its physical and production parameters that we can influence through the digital environment. Since the concept of Industry 4.0 is the basic parameter 
of intelligent enterprises and the digital twin is the core of Industry 4.0, we can directly influence real-time production and adapt it over the digital environment as we need it. This is an essential characteristic of a digital twin [8].

\section{$5 \quad$ Factory Twin}

The Factory Twin concept is an extension of the digital twin. As mentioned in the previous chapter, the digital twin initially originated to create a digital twin product. But Factory Twin is a concept that deals with the design of manufacturing and logistics systems with the help of a digital twin. The whole concept consists of three basic parts, respectively worlds. The difference between a digital business and a digital twin is just adding a virtual world to the real and digital world. This is the fundamental difference between the two concepts. Factory Twin therefore consists of the digital, real and virtual worlds [9].

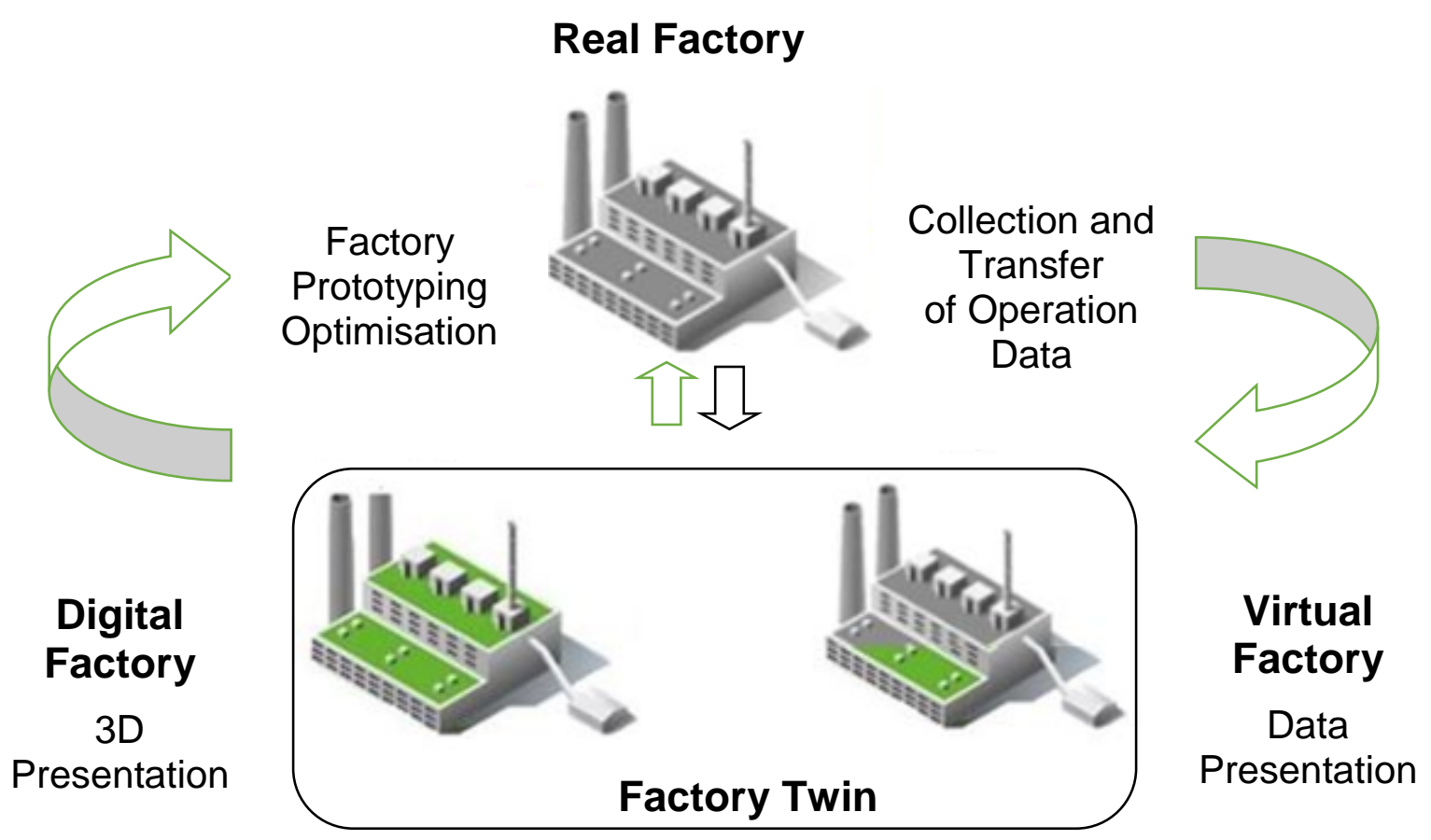

Figure 2 - Factory Twin

At the beginning of the concept when designing new production companies, the basic parameters for designing a new production layout are defined, where the whole concept is subsequently digitized and planned. With the help of dynamic simulation, the best option is selected and in the next step, it is all realized in the real world. Between these steps, there is still virtual training of employees. This means that after designing the production layout, employees in the virtual world will be able to experience how their role in the real business will take place. This reduces real-time training and saves costs. Also, digitization itself reduces the start of new production, which saves both 
costs and time. The implementation of these steps in the real environment is followed by the last step of this concept, monitoring, and analytics. An essential part of data collection in intelligent enterprises is the RTLS system, which is used to monitor and position objects in real-time. This system is mainly used for logistics processes or in warehouse management. Another basic system is RFID, which monitors product movement from input to output. Information control systems of production machines and equipment are used to optimize production. Whether it is a classic MES system or modern control systems, they all fulfil the same role. Various types of sensors, sensors, and sensors are used to monitor the physical parameters of machines and equipment. By linking all this data to a 3D project in a digital model, we get a digital twin or Factory Twin concept. With the help of emulation, we can influence customer requirements in real-time and thus adapt the production process as we need it, which is the main task of the digital twin [10].

\section{Discussion}

As is could see, these different benefits augur well for all factories and therefore the world is moving towards Industry 4.0. The challenge to begin may seem daunting. The nearly limitless configurations of smart factory solutions provide a number of pathways to proceed on the journey that need to be de-fined, planned, and executed at a pace suitable to the organization and the challenge or opportunity. As manufacturers consider how to build their smart factory, they can begin with the following steps:

- Think big, start small, and scale fast but stay grounded in the specific needs of the factory.

- Don't just begin and end with the technologies.

- Think outside the four walls.

\section{Conclusion}

Far from being an "end state," the smart factory is an evolving solution - one that taps into multiple features such as agility, connectedness, and transparency. At a high level, the dynamic nature of the smart factory speaks to an unending call for creative thinking: imagining the possibilities of the nearly endless configurations that a smart factory solution makes plausible. Investing in a smart factory capability can enable manufacturers to differentiate themselves and function more effectively and efficiently in an ever more complex and rapidly shifting ecosystem. 


\section{Acknowledge}

This work was supported by the Slovak Research and Development Agency under the contract No. APVV-16-0488.

\section{References}

[1] The smart factory - Responsive, adaptive, connected manufacturing [online] Deloitte. University Press, 2017, [cit. 7. 8. 2019], https://www2.deloitte.com/content/dam/insights/us/articles/4051 The-smartfactory/DUP The-smart-factory.pdf

[2] Soliman, F., Youssef, M. A., Internet-based e-commerce and its impact on manufacturing and business operations. Industrial Management \& Data Systems, 2003, vol. 103, no. 8-9, p. 546-552. ISSN 0263-5577.

[3] Horváthová, B., Dulina, L'., Krajčovič, M., Kasajová, M. The impact of Industry 4.0 on work activities. In: Aktuálne otázky bezpečnosti práce: 31. medzinárodná konferencia BOZP. Košice: Technická univerzita v Košiciach. p. 1-6. ISBN 978-80-553-2784-6.

[4] Furmannová, B., Gabajová, G., Gašo, M. Production company and bionic systems. In: Technológ, 2019, roč. 11, č. 2, p. 29-32. ISSN 1337-8996.

[5] Wang, S., Wan, J., Li, D., Zhang, Ch. Implementing Smart Factory of Industrie 4.0: An Outlook. International Journal of Distributed Sensor Networks, 2016. ISSN 1550-1329.

[6] Kováčová, L., Bubeník, P. Knowledge as a tool for increasing company performance. In: Invention for enterprise, Žilina: CEIT Stredoeurópsky technologický inštitút, 2018, p. 82-85. ISBN 978-80-89865-08-6.

[7] Radziwon, A., Bilberg, A., Bogers, M., Madsen, E. S. The Smart Factory: Exploring Adaptive and Flexible Manufacturing Solutions. In: 24th DAAAM International Symposium on Intelligent Manufacturing and Automation, 2013 Procedia Engineering, 2014, vol. 69, p. 1184-1190. ISSN: 1877-7058.

[8] Gregor, T., Gregor, M., Mačuš, P., Michulek, T. CEIT Smart Factory. In: ProlN, 2017, leden, p. 14-18.

[9] Gregor, M., Mačuš, P. Digitálne dvojča a Factory Twin. [online] 2019, [cit. 7. 8. 2019] Available from: https://www.mmspektrum.com/clanek/digitalnedvojca-factory-twin.html

[10] Hodoň, R., Žalman, R., Štefánik, A. The Benefits of Emulation in Logistics Systém. 2019. In: Invention for enterprise, Žilina: CEIT Stredoeurópsky technologický inštitút, 2019, p. 60-64. ISBN 978-83-66429-17-2.

[11] Seemann, P., Štofková, Z., Biňasová, V. Future of globalization and its implications for world business and management education. In: Globalization and its socio-economic consequences. Part 1. - Economic impact of migration, Žilina: Žilinská univerzita v Žiline, p. 350-357. ISBN 97880-8154-249-7. ISSN 2454-0943. 